\title{
Spiritual Well-Being and Depression among Middle Aged People
}

\author{
Nelofar Bashir ${ }^{1}$, Humera Shafi ${ }^{2}$, Usmat Yousuf ${ }^{3}$, \\ Sakeena Parveen ${ }^{3}$, Kulsum Akhter ${ }^{3}$
}

\section{ABSTRACT}

The aim of the present research was to study spiritual well-being and depression among middle aged people. 100 middle aged persons were taken for the present study. The tools used were Spiritual wellbeing Scale (Paloutzian \& Ellison, 1982), Beck Depression Inventory-III (Beck, Steer and Brown, 1996). The result revealed that out of 100 middle aged people, $79 \%$ showed average level, and $21 \%$ showed high level of spiritual well being. Also it was found that out of the total sample $68 \%$ fall in the minimal level of depression, $16 \%$ fall in the mild level, $10 \%$ fall in the moderate level of depression and the remaining $6 \%$ of the sample fall in the severe level of depression. Further, results of the study revealed significant negative correlations of spiritual well being with depression among middle aged people. Furthermore results did not reveal any significant differences for spiritual well-being and depression among middle aged people as far as their gender is concerned.

Keywords: Spiritual well-being; Depression.

Spirituality is defined as an integral dimension of the health and well-being of every individual (Skokan \& Bader, 2000). Spiritual well-being is an indication of an individual's quality of life in the spiritual dimension. According to Fehring, Miller, and Shaw (1997), spiritual well-being has two components: a vertical dimension that involves a relationship with a higher being or God, and a horizontal dimension that involves a sense of purpose and meaning in life. Spiritual wellbeing is not synonymous with belief or practice in the particular aspects of a religion. Instead, it is an affirmation of life in a relationship with God, self, community, and environment. It nurtures wholeness (Blazer, 1991). Spiritual well-being is about our inner life and its relationship with the wider world. It includes our relationship with the environment; spiritual well-being does not just reflect religious beliefs although for people of a religious faith. It is considered to be a primary coping resource on the journey of recovery and healing. It can be practiced in numerous ways with its main purpose being to find purpose and meaning in life. The improvement in the

\footnotetext{
${ }^{1}$ Ph. D. Research scholar, Dept of Psychology, University of Kashmir, Srinagar

${ }^{2}$ Sr. Asst Professor, Dept of Psychology, University of Kashmir, Srinagar

${ }^{3}$ PG student, Dept of Psychology, University of Kashmir, Srinagar

*Responding Author

(C) 2016 I N Bashir, H Shafi, U Yousuf, S Parveen, K Akhter; licensee IJIP. This is an Open Access Research distributed under the terms of the Creative Commons Attribution License (http://creativecommons.org/licenses/by/2.0), which permits unrestricted use, distribution, and reproduction in any Medium, provided the original work is properly cited.
} 
practices of religion and spirituality will have the positive effect on both mental and physical health (Seybold, and Hill, 2001 ;). Older adults believe that prayers can heal both physical and mental illness, and the relationship with God forms the foundation of their Psychological well being( Mackenzie E.R et al 2000) . Lower depression scores were predicted by higher levels of religious and spiritual coping, greater social support, higher income, good physical health, and lower daily spiritual experiences among older adults.( Roh.S. 2000). Depression is a state of low mood and aversion to activity that can affect a person's thoughts, behavior, feelings and sense of well-being (Salmans, 1997). Depressed people feel sad, anxious, empty, hopeless, worried, helpless, worthless, guilty, irritable, hurt, or restless. They may lose interest in activities that once were pleasurable, experience loss of appetite or overeating, have problems concentrating, remembering details, or making decisions, and may contemplate, attempt, or commit suicide. During stressful circumstances, religious involvements have more positive impact on mental health (Almedia, et al.). Research revealed negative correlation between spiritual well-being and depression, and between health status and depression among elderly women (Jang,I.S 2004). Depression was negatively associated with the domains of intrinsic beliefs, such as belief in high power, the importance of prayer and finding meaning in times of hardship (Doolittle B.R \& Farrel 2004). Depressive symptoms was significantly associated with poorer religious coping, and worse spiritual well-being (Yi Ms, Luckhaupt, S. E 2006).

\section{OBJECTIVES OF THE STUDY:}

1. To assess the spiritual well being among middle aged people.

2. To assess the depression among middle aged people.

3. To study the relationship between spiritual well being and depression among middle aged people.

4. To study the significance of difference in relation with spiritual wellbeing and depression among middle aged people with respect to their gender.

\section{Hypotheses}

$\mathbf{H}_{\mathbf{0 1}}$ There is no significant relationship between spiritual well being and depression among middle aged people.

$\mathbf{H}_{\mathbf{0 2}}$ There is no significant difference in spiritual well being of middle aged people as far as their gender is concerned.

$\mathbf{H}_{\mathbf{0 3}}$ There will be no significant difference in depression of middle aged people as far as their gender is concerned.

\section{Sample}

The study was conducted on a sample of 100 middle aged people

\begin{tabular}{|l|l|l|l|}
\hline Demographic Variables & & Number (N) & \multicolumn{1}{c|}{ Total } \\
\hline Age & $46-65$ years & 100 & 100 \\
\hline \multirow{2}{*}{ Gender } & Male & 73 & 100 \\
\cline { 2 - 3 } & Female & 27 & \\
\hline
\end{tabular}




\section{Description of Tools}

1) Spiritual well being Scale: The Spiritual wellbeing Scale (SWB) was used to gather data for the present study developed by Raymond, Paloutzian and Ellison (1982). The spiritual wellbeing scale (SWB) consist of 20 items, individually measured on a 6 - point likert scale, ranging from 'strongly agree' to 'strongly disagree'.

The spiritual wellbeing scale (SWB) includes following two subscales.

A. Religious Wellbeing (RWB) 10 questions.

B. Existential Wellbeing (EWB) 10 questions.

2) Becks Depression Inventory ( $2^{\text {nd }}$ edition): The Scale (BDI- II) was developed by Aaron T. Beck, Robert A. Steer and Gregory K. Brown (1996). It is a 21- item self report instrument for measuring the severity of depression. The BDI - II is scored by summing the ratings for 21 items, and each item is rated on a 4 -point scale ranging from 0 to 3 .

\section{Statistical Analysis}

In proposed study central tendencies, (mean, standard deviation), Pearson's correlation coefficient and T-test were used.

\section{RESULTS AND INTERPRETATION:}

Table 1 Showing percentage of spiritual wellbeing among middle aged people across various levels

\begin{tabular}{|l|l|l|}
\hline \multirow{2}{*}{ Levels } & Spiritual Wellbeing \\
\cline { 2 - 3 } & $\mathbf{N}$ & \%age \\
\hline Low & 0 & $0 \%$ \\
\hline Average & 79 & $79 \%$ \\
\hline High & 21 & $21 \%$ \\
\hline
\end{tabular}

The above table 1 shows that out of total sample $0 \%$ fall at low level of spiritual wellbeing, $79 \%$ fall on Average level, and 21\% fall at high level of spiritual wellbeing.

Table 2: Showing percentage of depression among middle aged people across various levels.

\begin{tabular}{|l|l|l|}
\hline \multirow{2}{*}{ Levels } & Depression \\
\cline { 2 - 3 } & N & \%age \\
\hline Minimal & 68 & $68 \%$ \\
\hline Mild & & $16 \%$ \\
\hline Moderate & 16 & $10 \%$ \\
\hline Severe & 10 & $6 \%$ \\
\hline
\end{tabular}

The above table 2 reveals that out of the total sample $68 \%$ fall in the minimal level of depression, $16 \%$ fall in the mild level of depression, $10 \%$ fall in the moderate level of depression and the remaining $6 \%$ of the sample fall in the severe level of depression. 
Table 3: Showing Correlation between Spiritual wellbeing and Depression among middle aged people. $(N=100)$

\begin{tabular}{|l|l|}
\hline Variable & Depression \\
\hline Spiritual Wellbeing & $\mathrm{r}=-0.28^{*}$ \\
\hline
\end{tabular}

$* . \mathrm{P} \leq 0.05$ level of significance

The above table shows the correlation coefficient between spiritual wellbeing and depression, which is -0.28 . The correlation is negative and is significant at 0.05 level. Hence our Hypothesis $\mathrm{H}_{01}$ which states that there is no significant relationship between spiritual well being and depression among middle aged people stands rejected.

Table 4 Showing Comparison of Mean Scores of Spiritual wellbeing as for as gender of middle aged people is concerned

\begin{tabular}{|l|l|l|l|l|l|l|}
\hline Variable & Group & N & Mean & SD & Df & t-value \\
\hline \multirow{2}{*}{$\begin{array}{l}\text { Spiritual } \\
\text { Wellbeing }\end{array}$} & Male & 73 & 89.45 & 10.40 & 98 & $0.92^{\text {NS }}$ \\
\cline { 2 - 5 } & Female & 27 & 89.74 & 14.44 & & \\
\hline
\end{tabular}

$* \mathrm{P} \leq 0.05$ level of significance

Table 4 shows that, there is no significant difference in Spiritual Wellbeing as far as gender of middle aged people is concerned. . Thus our null hypothesis $\mathrm{H}_{02}$ which states that there is no significant difference in spiritual well being of middle aged people as far as their gender is concerned stands accepted.

Table 5. Showing Comparison of Mean Scores of Depression as for as gender of middle aged people is concerned

\begin{tabular}{|l|l|l|l|l|l|l|}
\hline Variable & Group & N & Mean & SD & df & t-value \\
\hline \multirow{2}{*}{ Depression } & Male & 73 & 10.49 & 8.14 & 98 & $0.09^{\text {NS }}$ \\
\cline { 2 - 5 } & Female & 27 & 14 & 9.17 & & \\
\hline
\end{tabular}

NS $=$ Not Significant

Table 5 .shows that, there is no significant difference on Depression as far as gender, of middle aged people is concerned. Thus our null hypothesis $\mathrm{H}_{03}$ which stands that there will be no significant difference in depression of middle aged people as far as their gender is concerned stands accepted.

\section{DISCUSSION AND CONCLUSION}

The present research endeavor was aimed to assess and to study the relationship between spiritual well being and depression among middle aged people. The study revealed that, 79\% of the subjects fall in Average level, and 21\% are in high level of spiritual wellbeing, while as no subject fall in low level of spiritual well being. Further, with respect to depression, it was found that out of 100 middle aged people $68 \%$ of people showed minimal level of depression, $16 \%$ of people showed mild level of depression, $10 \%$ showed moderate level of depression \& 6\% of people showed severe level of depression. The correlation of spiritual well being and depression among middle aged people was found to be significantly negative. This finding is consistent with 
the study conducted by Callen, et al. (2003).Also Lower depression scores were predicted by higher levels of religious and spiritual coping, greater social support, higher income, good physical health, and lower daily spiritual experiences among older adults.( Roh, S. 2000). Our results also revealed that there was insignificant difference in spiritual wellbeing and depression among middle aged people as far their gender is concerned. This finding contradicts most of the studies which indicated that females tend to score higher on depression than males (Kessler, et al., 1994). A study that was conducted in Kashmir also revealed higher prevalence of depression among females (64.21\%) than in males (68.64\%) (Amin and Khan, 2009).

\section{REFERENCES}

Almedia, A. M., Neto, F. L., \& Koenig, H. G. (2006). Religiousness and mental health: a review, Revista Brasileira de Psiquiatria, 28(3), doi: 10.1590/S1516-44462006005000006.

Amin, S. \& Khan, A. W. (2009). Life in conflict: Characteristics of Depression in Kashmir. International Journal of Health Sciences, 3(2).

Beck, A. T., Steer, R. A., \& Brown, G. K. (1996). Manual for Beck Depression Inventory (second edition). The psychological Corporation. Harcourt Brace and Company, San Antonio.

Blazer, D., Bachar, J. R., Hughes, D. C. (1987). Major depression with melancholia: a comparison of middle-aged and elderly adults. J Am Geriatr Soc, 35, 927-32.

Bufford, R. K., Paloutzian, R. F., \& Ellison, C. W. (1991). Norms for the Spiritual Well-Being Scale. Journal of Psychology and Theology, 19(1), 1991, 56-70

Callen, B. L., Mefford, L., Groër, M., \& Thomas, S. (2011). Relationships among stress, infectious illnesses, and religiousness/spirituality in community dwelling elderly. Research in Gerontological Nursing, 4(3) 195-206.

Doolitle, B.R., \& Farrell, M. (2004). The association between spirituality and depression in an urban clinic, The Journal of Clinical Psychiatry,6(3),114-118.Retrieved April 4, 2013 from http:// www.ncni.nlm.gov/

Fehring, R. J., Miller, J. F., \& Shaw, C. (1997). Spiritual Well being, Religiosity, Hope Depression and other Mood States in Elderly People Coping with Cancer. Oncol Nurs forum, 24(4), 663-71.

Jang, I.S. (2004).A study on spiritual well being, depression and health status of elderly women in a community, Korean Journal of Women Health and Nursing, 10(2),91-98.Retreived May 8, 2013 from http:// journal.women-health-nursing.or.kr/

Kessler, R. C., Mc Gonagle, K. A., Zhao, S., Nelson, C. B., Hughes, M., Eshleman, S., Wittchen, H., \& Kendler, K. S. (1994). Lifetime and 12-month prevalence of DSM-III-R psychiatric disorders in the United States: Results from the National Comorbidity Survey. Archives of General Psychiatry, 51, 8-19.

Mackenzie, E.R., Rajagopal, D.E., Meibohm, M., \& Lavizzo, M.R. (2000). Spiritual support and Psychological well being: older adult's perception of the religion and health connection, Alternative therapies in health and medicine, 6(6), 37-45. Retrieved April 4, 2013 from http:// www.ncni.nlm.nih.gov/ 
Roh, S. (2000). The impact of religion, spirituality, and social support on depression and life satisfaction among Korean immigrant older adults. (Doctoral dissertations, New York University, 2010). Retrieved May 14, 2013 from http:// http://gradworks.umi.com

Salmans, S. (1997). Depression: Questions You Have - Answers You Need. People's Medical Society. ISBN 978-1-882606-14-6.

Seybold, K. S., \& Hill, P. C. (2001). The role of religion and spirituality in mental and physical health, Psychological Science, 10(1), 21-24.

Shokan, L., \& Bader, D.(2000).Spirituality and healing. Health progress, 81(1) ,38-42.

Yi, M.S., Luckhaupt, S.E., Mrus, J.M., Muller, C.V., Peterman, A.H., Puchalski, C.M., \& Tsevat, J. (2006). Religion, spirituality, and depressive symptoms in primary care house officers. Journal of the Ambulatory Pediatric Association, 6(2), 84-90. 